\title{
TOMOGRAPHIC ASSESSMENT OF REINFORCEMENT OF ACRYLIC RESIN DENTURE BASE FOR PALATELESS IMPLANT LOCATOR RETAINED MAXILLARY OVER DENTURE
}

\author{
Hesham E. Alameldeen* and Amany Khalifa Alsayed**
}

\begin{abstract}
Objectives: This study was conducted to evaluate the effect of metallic (cobalt chromium), glass fiber and nano zirconia oxide reinforcement of acrylic resin denture base on the peri-implant crestal bone level changes in palateless locator retained maxillary over denture.

Materials and Methods: Twenty-one completely edentulous male patients with maladaptive experience to maxillary dentures were selected to participate in this study. For all patients maxillary four implant-retained overdenture was constructed following the same basic principles. Every patient received four implants, two in the canine region with $(3.6 \mathrm{~mm}$ in diameter \& $12 \mathrm{~mm}$ in length), and two in the second premolar region with $(4.5 \mathrm{~mm}$ in diameter \& $8 \mathrm{~mm}$ in length); (Tiologic $\AA^{\circledR}$ Implants, Dentaurum, Ispringen, Germany) following the two stage surgical technique. Metal (cobalt chromium) reinforced over denture was constructed for the first group, while 5\% fiber reinforced acrylic resin denture was constructed for the second group and Overdenture was reinforced using $5 \%$ of nano $\mathrm{ZrO}_{2}$ for the group three patients. . Follow up visits were scheduled twelve and twenty four after implant loading for inspection of the prosthesis and radiographic evaluation Peri-implant crestal bone level changes were assessed using intra-oral radiographs taken with the standardized long cone paralleling technique using custom made acrylic template and the Rinn-xcp system.
\end{abstract}

Results: The findings of the present study demonstrates that all the studied denture base reinforcement materials individually showed significance bone loss around implants $(p<0.05)$ after 12 months follow up period. Insignificant increase in the calculated means the peri-implant bone height changes of was evident during the intervals $12-24$. Group I Metal (cobalt chromium) reinforced heat cured acrylic resin denture showed more peri-implant bone loss compared to group II glass fiber and group III nano zirconia oxide reinforced acrylic resin denture base reinforcement. Although group II glass showed more peri-implant bone loss compared to group III glass during the follow up period statistically in significant difference between the two studied groups was found

Conclusion: Within the limitations of this study, reinforcement of polymethyl methacrylate denture base with glass fiber or nano zirconia oxide should be considered in palateless implant retained maxillary over denture. Further clinical studies for newest reinforcement materials are necessary to ensure the effect of reinforcement within dental prostheses.

* Associate Professor of Prosthodntics, Faculty of Oral and Dental Medicine, Future University.

** Assistant professor of Oral \& Maxillofacial Surgery, Faculty of Oral and Dental Medicine Modern University for Technology and Information 


\section{INTRODUCTION}

Nowadays, the use implant retained overdenture has been considered an appropriate treatment of choice for rehabilitation of completely edentulous maxilla. ${ }^{(1-3)}$ Numerous studies have shown that U-shaped palate-less maxillary implant-retained overdenture is an effective solution and leads to significant improvement of patient-based outcomes, increased quality of life, and provide easier access for oral hygiene. ${ }^{(4-7)}$

A systematic review on maxillary implant-retained overdentures showed that there are no specific guide lines for the number of implants necessary to support a maxillary implant-retained overdenture. Some authors have reported clinical success as determined by survival of prostheses and implants in treating patients with a palate-less maxillary implant-retained overdenture with a minimum of 4 supporting implants, while others recommended the use of palatal coverage when 4 or less implants are used. ${ }^{(8)}$

Despite different recommendations on the number of implants used in an implant-retained overdenture, other complicating factors in the maxilla can affect the decision making regarding the sufficient number of implants in a palate-less maxillary implant-retained overdenture. These factors include: the lower quality of bone in the maxilla, the power of the muscles of mastication, the type of dentition of the opposing arch and resulting occlusal forces, the type and number of attachments, the inter-arch distance, the relationship between the shape of the residual ridge and form of the dental arch and implant angulation. These factors should be considered when deciding the number and distribution of implants in a maxillary implant-retained overdenture. ${ }^{(8)}$ Damghani et $\mathrm{al}^{(9)]}$ in stress analysis study concluded that the distribution of implants had a significant effect on the force measured on the palate of overdenture retained by Locator attachments and suggested use of 4 implants separated by $16 \mathrm{~mm}$. or more to retain maxillary overdenture.
Although palate-less maxillary implant-retained overdenture is an effective solution to improve taste perception and gagging problems, one frequent problem that occurs with heat cured acrylic resin in overdenture prostheses is denture deformation , fracture of acrylic resin denture base occurs due to initiation and propagation of cracks from areas of high stress concentration over the implants. In addition the increased load concentration over the implants may cause loosening of the attachments mucosal ulceration and implant overload. ${ }^{(10-12)}$

Many additives have been suggested to enhance the properties of denture base resin. The aim was to improve the impact strength, fatigue resistance and transverse strength of the acrylic resin. Modification of the conventional heat cured denture base to produce a co-polymerized high impact strength resin, or reinforcing the denture base with carbon fibers, glass fibers, ultra- high molecular , metal powders and the incorporation of in organic nanoparticles have been suggested. Denture base reinforcement improves the rigidity of the base and distributes the functional forces to the implants. ${ }^{(10-14)}$

Reinforcement of acrylic resin with fibers has been reported to improve the flexural and impact strength as well as the fatigue resistance of the resin fibers are supplied in form such as nylon, polyethylene, polyamide fiber, and particularly glass fiber. Several glass fibers are supplied in form of woven, loose and continuous such as roving or fiber bundle to strengthen dental polymers. ${ }^{(14)}$

Numerous studies showed that glass fiber reinforcement of acrylic resin denture bases improved the mechanical properties of acrylic resin denture bases. The improvement was detected in the; elasticity and hardness, impact strength, rigidity, fatigue resistance and flexural strength and modulus. (15-17) Glass fiber reinforcement also affects various physical properties such as dimensional stability and water sorption. The importance of accuracy and dimensional stability is a prime consideration when 
attempting to reinforce the polymethylmethacrylate polymers with glass fibers. ${ }^{(14,18,19)}$

Recently, much attention has been directed toward the incorporation of in organic nanoparticles into PMMA to improve its properties. One of the most recent introductions to the dental ceramics family is zirconia. The incorporation of zirconia in various dental materials was found to be biocompatible and improved the mechanical properties especially the fracture resistance. Stabilizing oxides are added to zirconia to retain a metastable condition at room temperature, enabling a phenomenon called transformation toughening to occur. The partially stabilized crystalline zirconia exhibits good response to mechanical stimuli, such as tensile stress at crack tips resulting in local increase in volume of approximately $4 \%$. This increase in volume closes the crack tips, effectively blunting crack propagation. It is this transformation-toughening process which gives zirconia its strength and toughness. Compared to alumina, zirconia has twice the flexural strength, partly because of its grain size and the transformation-toughening mechanism. ${ }^{(14,20,21)}$

The addition of nano zirconia oxide $(\mathrm{ZrO} 2)$ to improve mechanical properties and to achieve maximum radio-opacity with minimum effect on mechanical properties was attempted. Nano $\mathrm{ZrO} 2$ was used because it is excellent biocompatible material also because of being white is less likely to alter esthetic. ${ }^{(22,23)}$

Stresses transmitted to the abutments is multifactorial with numerous etiologies currently debated in the dental literature, among these factor is the denture base material. Accordingly, this study was conducted to evaluate and compare the effect of metallic (cobalt chromium), glass fiber and nano zirconia oxide reinforced acrylic resin denture base reinforcement on the peri-implant crestal bone level changes in palateless locator retained maxillary over denture.

\section{MATERIALS AND METHODS}

Twenty one completely edentulous male patients with maxillary denture adaptation problems were selected to participate in this study. All patients were rehabilitated by mucosa supported mandibular complete denture and implant retained maxillary overdenture by four implants installed in the canine and second premolar region and retained by locator attachment.

Patients were selected in this study if their clinical condition met the following inclusion criteria: Age ranged between $65-70$ years, exhibited Angle class I ridge relationship, patients had either Ushaped or rounded alveolar arches, adequate inter arch space. The residual alveolar ridge exhibited adequate height and width and was covered with firm fibrous mucoperiosteum. All patients were in a good acceptable general health, with no psychological disorders or neuromuscular in co-ordination. Exclusion criteria included systemic diseases that may compromise implant surgery (such as severe liver, kidney and blood disorders and uncontrolled diabetes), history of chemotherapy or radiation therapy, uncooperative patient, history of parafunctional habits, temporomandibular joint disorders and active smoker.

All patients were evaluated for the bone quality and quantity by cone beam radiographs (CBCT) to examine the condition of upper ridge and ensure adequate width and length and relation to the maxillary sinus wall.

Detailed information about the treatment was given to all the patients; the surgical and prosthetic steps, the risks and the benefits were explained. All the patients were motivated to the treatment and were informed that they will be a part in a study that needs their best co-operation. All the patients agreed to share and follow the recommendations and instructions given to them in the form of signed consent.

The selected patients were randomly divided into three equal groups by close envelopes, according to 
the material used for over denture reinforcement. Metal (cobalt chromium) reinforced over denture was constructed for the first group, while glass fiber reinforced acrylic resin denture was constructed for the second group and Overdenture was reinforced using $5 \%$ of nano $\mathrm{ZrO}_{2}$ for the group three patients.

Old dentures were evaluated and adjusted. Computer guided surgical stent for the proposed implant site was constructed by using 3D. Construction of the radiographic stent and CBCT imaging was done by duplication of maxillary denture into radiographic stent. Cold cured clear acrylic resin was mixed with radio-opaque material (barium sulphate) and packed in the mold. The virtual planning for proper treatment plan were determined by the Software allows rotate of the 3D images from all angles, to simplify the selection of four implant's location, length and diameter according to the patient's bone quantity and approximation to maxillary sinus. (Fig 1).
Cone beam computed tomography (CBCT) with the maxillary radiographic stent in place for the construction of computer guided surgical stent for the proposed implant site by using 3D printer.

After pre-surgical preparation (mouth rinses 3 times /day, oral antibiotics $2 \mathrm{~g}$ /day started one hour before surgery and continued for three days

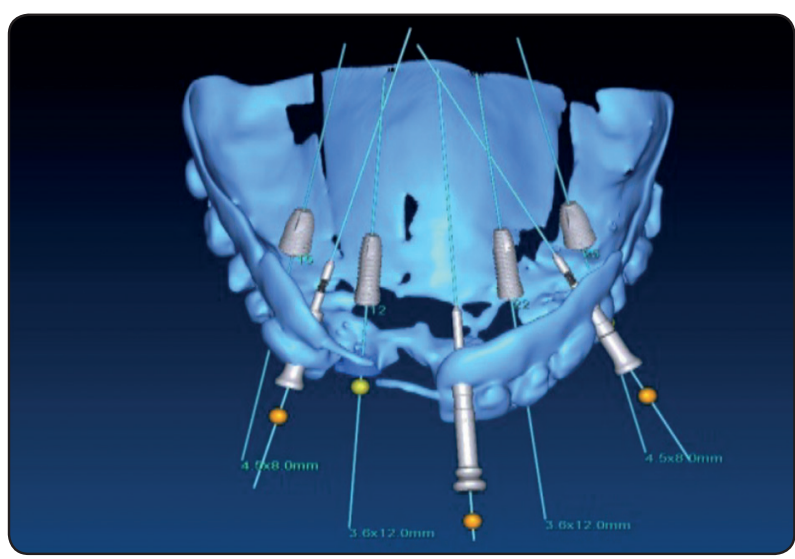

Fig. (2): Virtual planning with stent in place.

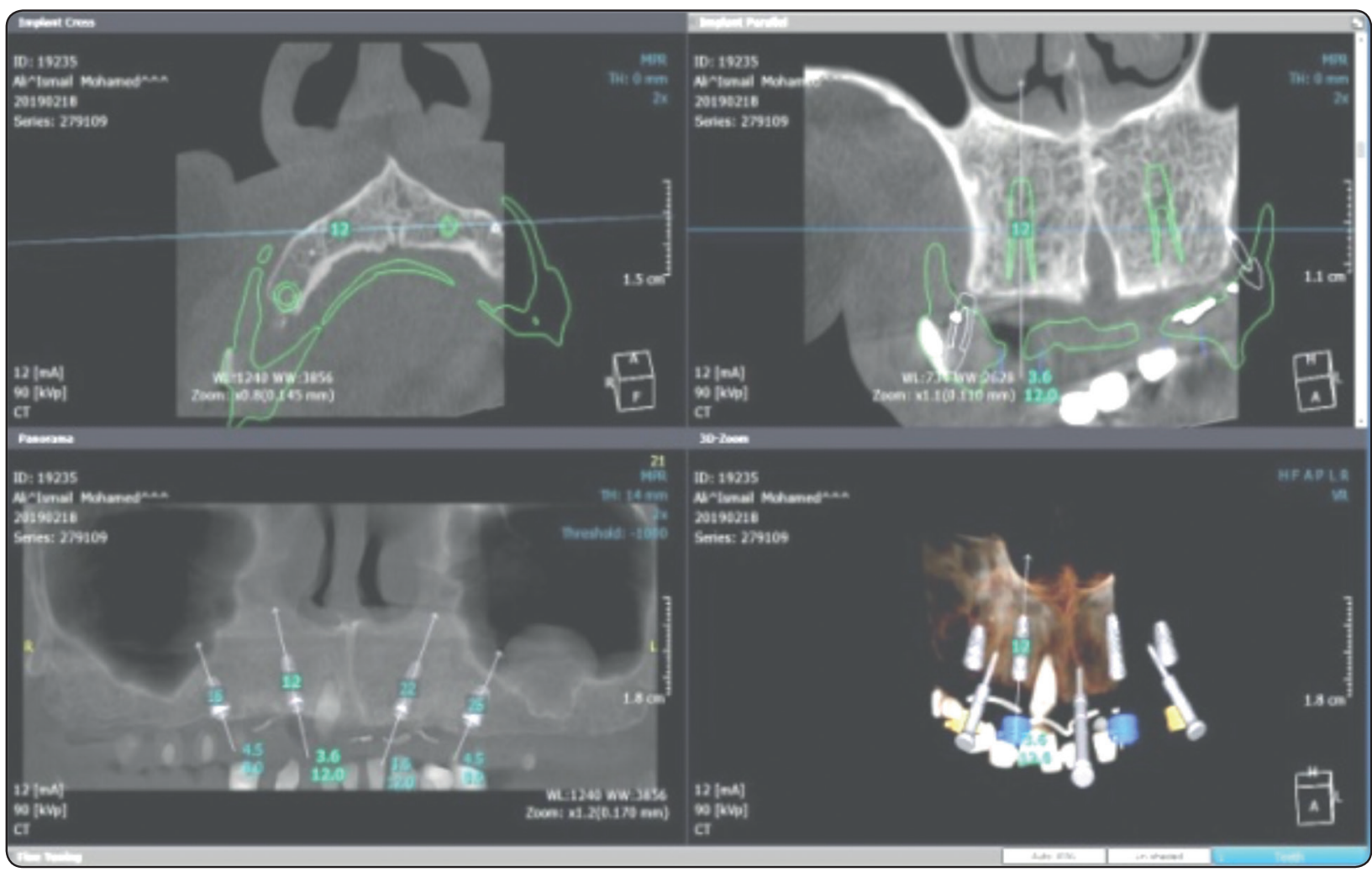

Fig. (1): Virtual planning for the implant placement. 
postoperatively), following the report provided with the surgical guide sequential drilling was done for each implant . Every patient received four implants, two in the canine region with $(3.6 \mathrm{~mm}$ in diameter \& $12 \mathrm{~mm}$ in length), and two in the second premolar region with $(4.5 \mathrm{~mm}$ in diameter \& $8 \mathrm{~mm}$ in length); (Tiologic ${ }^{\circledR}$ Implants, Dentaurum, Ispringen, Germany). After implant surgery, Implant stability quotient (ISQ) was assessed by resonance frequency analysis (RFA, OsstellTM; Osstell AB, Gothenburg, Sweden) after attaching the Smart Peg to the implant. Cone beam radiograph was done immediately postoperative to verify the surgical guide accuracy by super impositioning of the preoperative virtual implant planning and postoperative implant insertion ${ }^{(24)}$

A functional healing period was allowed to progress for four months, through which the patients were wearing their dentures lined by tissue conditioning material. After four months, the prosthesis fabrication procedures were performed to all the patients following the same basic principles.

For group I patients after making the secondary impression, master cast was duplicated to produce the refractory cast and horseshoe-shaped wax pattern was designed, invested and cast in cobalt chromium alloy. Centric occlusion was developed at centric relation. Modified cusped acrylic teeth were used and balanced on semi-adjustable articulator for centric and eccentric positions following the lingualized concept of occlusion. When satisfactory trial was attained the waxed up denture was flasked and wax elimination was carried out.

Dentures were processed using heat cured acrylic resin for group one. Heat cured acrylic resin was packed into the flask and heated at $78 \mathrm{C}^{\circ}$ for eight hours following the long curing cycle.

For group II patients, fiber reinforced acrylic resin over denture was constructed. Two mm glass fibers in length were treated by preparing a $95 \%$ ethanol solution and adjusting the $\mathrm{PH}$ value to 5 with acetic acid. Silane was added by stirring to yield a final concentration of $2 \%$. The solution was kept for 5 min for hydrolysis and silanol formation. Fiber particles were silanated by stirring them in the solution for $2 \mathrm{~min}$ and then decaoting the solution into filter paper, the particles were rinsed twice with ethanol and the silane layer was cured $10 \mathrm{~min}$ at $110 \mathrm{c}$. The dried silanated fibers were added to the monomer first and was calculated as $5 \%$ weight of the monomer polymer mix was made by $1: 2.5$ monomer polymer mix by weight. The mix was packed in to flask at the dough stage and cured using the long curing cycle.

For group III patient's overdenture was reinforced using $5 \%$ of $\mathrm{Nano} \mathrm{ZrO}_{2}$ the desired percent of Nano $\mathrm{ZrO}_{2}$ powder (5\% by weight) was treated with silane coupling agent. A solution of $0.3 \mathrm{gm}$. of zirconia coupling agent in $100 \mathrm{ml}$ of acetone was used to treat $30 \mathrm{~g}$ of zirconia powder $\left(\mathrm{ZrO}_{2}\right)$. The oxide powder was stirred in the coupling agent/acetone solution with a magnetic stirrer, for 60 minutes, after which acetone was completely evaporated using a rotary evaporator. ${ }^{(25)}$ Thorough mixing of the oxide powder with the acrylic polymer powder was carried out using porcelain mortar and pestle, then, the monomer was added to the mixture. The mix was packed in to flask at the dough stage and cured using the long curing cycle.

Patients were recalled after 24 hours, 3 days and one week after denture insertion to perform any needed adjustments. Two weeks later clinical remounting was carried out for occlusal adjustment to eliminate occlusal interference and provide free gliding from centric to eccentric positions.

At the second stage surgery implants were uncovered, implant stability was assessed and the conical healing abutments were screwed in position. The fitting surface of the denture was relieved opposite to the implants' sites. One week later, the conical healing abutments were replaced by the original locator abutment, locator housing 
with processing caps were snapped on the abutment and self-cured acrylic resin was used to directly pick up the attachment. Patients were instructed to close in centric until complete polymerization took place. The black processing male was removed from the metal housing and replaced by the nylon replacement insert. The denture base was trimmed into horseshoe -shaped pattern.

Patients were recalled frequently for postinsertion inspection and adjustment. Follow up visits were scheduled at time of denture insertion, one and two years after denture insertion for inspection of the prosthesis and radiographic evaluation. . Each time patients were recalled, clinical evaluation for the cases was carried out to inspect oral hygiene, denture bearing structures and implants. Dentures were evaluated, anterior clearance was checked and occlusal adjustment was performed.

Radiographic evaluation.: Peri-implant crestal bone level changes were assessed using intra-oral radiographs taken with the standardized long cone paralleling technique using custom made acrylic template and the Rinn-xcp system ${ }^{(26,27)}$ made at the time of implant loading and at the recall appointments.. The radiographic linear measurement from the implant shoulder to the first bone-to- implant contact was used to assess peri-implant crestal bone height changes at the mesial and distal aspect of each implant using Digora software system.

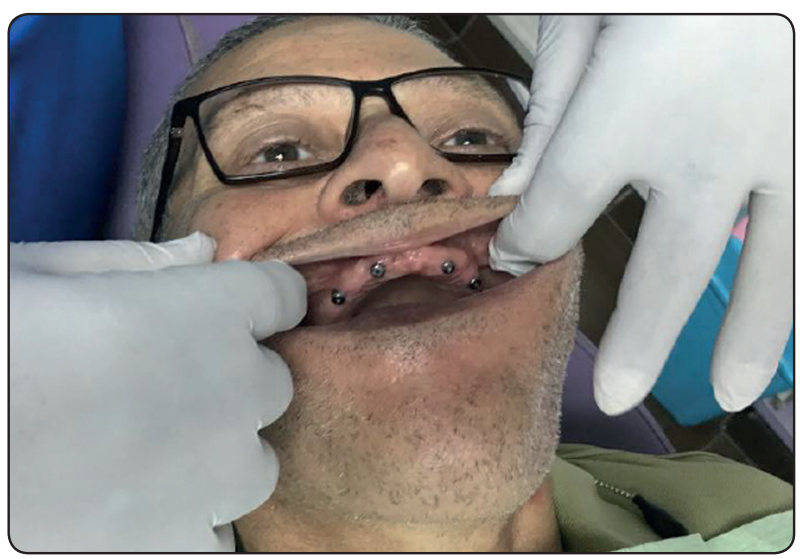

Fig. (3): Locator attachment in position (intra oral view)

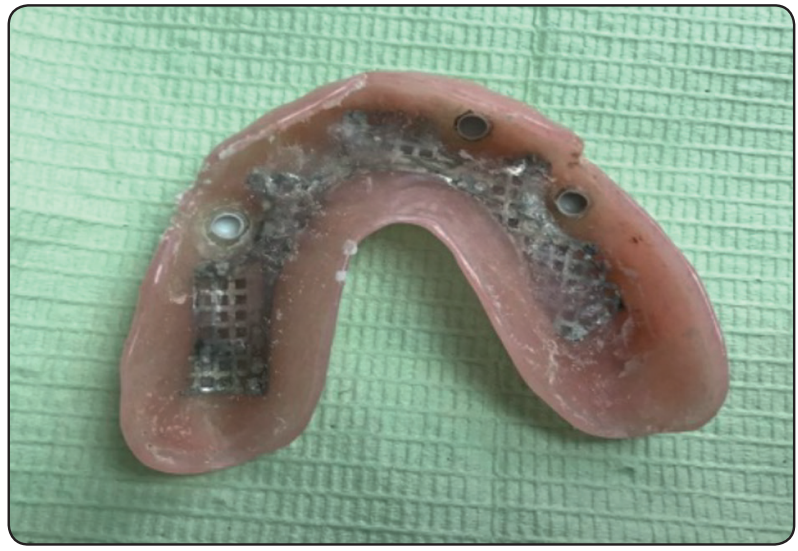

Fig. (4): Intaglio-surface of the maxillary palate-less over denture.

\section{Statistical analysis:}

Kolmogorov-Smirnova and Shapiro-Wilk tests was used to assess data normality, and data was assumed normally distributed. Student $T$ test was used to compare between mesial and distal peri-implant crestal bone level changes at follow up periods within groups. One way ANOVA test for repeated measures test was used to compare between follow up periods within groups and between groups when statistically significant it was followed by simple main effect analysis with Bonferioni correction. . The significance level was set at $\mathrm{p} \leq 0.05$.

\section{RESULT}

The results of this study are shown in tables (1 and 2). Since no statistical difference was detected between the mesial and distal peri-implant crestal bone level changes of the anterior and posterior implants they were added and the mean was obtained for statistical analysis.

The Mean difference and standard deviation of the effect of different reinforcement (group I metallic (cobalt chromium), group II glass fiber and group III nano zirconia oxide reinforced acrylic resin denture base) on peri-implant crestal bone level changes around posterior implants during the follow up period are shown in table 1 . Statistical 
analysis of bone height using ANOVA test for repeated measures revealed significant difference in bone height changes at the interval loading12 months follow up periods for all the studied groups $(\mathrm{P} \leq 0.05)$. Although the data obtained from table 1 revealed increase in the amount greater at the interval 12- 24 months follow up period, statistical analysis of the data using ANOVA test for repeated measures revealed no significance difference $(\mathrm{P} \geq 0.05)$ for the three studied groups. Comparing the three studied groups using ANOVA test table 1 , shows a statistically significant increase for group I metallic (cobalt chromium) $(\mathrm{P} \leq 0.05)$ during the follow up period. Although greater periimplant crestal bone level changes was detected for group II glass fiber compared to group III nano zirconia oxide reinforcement Simple main effect with Bonferrioni correction revealed insignificance difference $(P \geq 0.05)$.
The Mean difference and standard deviation of the effect of different reinforcement group I ( metallic cobalt chromium), group II (glass fiber) and group III( nano zirconia oxide) reinforced acrylic resin denture base on peri-implant crestal bone level changes around posterior implants during the follow up period are shown in table two. Statistical analysis of bone height using ANOVA test for repeated measures revealed significant difference in bone height changes at the interval loading12 months follow up periods for all the studied groups $(\mathrm{P} \leq 0.05)$. Although the data obtained from table 1 revealed increase in the amount greater at the interval 12- 24 months follow up period, statistical analysis of the data using ANOVA test for repeated measures revealed no significance difference $(\mathrm{P} \geq$ $0.05)$ for the three studied groups. Comparing the three studied groups One way ANOVA test revealed insignificance difference $(\mathrm{P} \geq 0.05)$ between groups as shown in table during the follow up period.

TABLE (1): Mean difference and standard deviation of the effect of different reinforcement on peri-implant crestal bone level changes s around posterior implant.

\begin{tabular}{|c|c|c|c|c|c|c|c|c|c|c|}
\hline Treatment modality & \multicolumn{2}{|c|}{ metallic (cobalt chromium) (Group I) } & \multicolumn{3}{|c|}{ Glass fiber (Group II ) } & \multicolumn{4}{|c|}{ nano zirconia oxide (Group III) } \\
\hline Time & Mean & S.D. & dt1 dt2 & Mean & S.D. & dt1 dt2 & Mean & S.D. & dt1 dt2 \\
\hline loading-12mon & 0.604 & 0.027 & A a & 0.565 & 0.005 & A & b & 0.513 & 0.002 & A b \\
\hline 12-24mon & 0.14 & 0.013 & B a & 0.12 & 0.024 & B & b & 0.13 & 0.026 & B b \\
\hline loading-24mon & 0.724 & 0.021 & A a & 0.685 & 0.017 & A & b & 0.643 & 0.013 & A b \\
\hline
\end{tabular}

S.D.= Standard deviation., Dt1 =Within group Dt2 = between groups Means with the same letter within each row are not significantly different at $(P \leq 0.05)$.

TABLE (2): Mean difference and standard deviation of the effect of different reinforcement on peri-implant crestal bone level changes s around anterior implant.

\begin{tabular}{|c|c|c|c|c|c|c|c|c|c|}
\hline Treatment modality & \multicolumn{3}{|c|}{ metallic (cobalt chromium) (Group I) } & \multicolumn{3}{|c|}{ Glass fiber (Group II ) } & \multicolumn{3}{|c|}{ nano zirconia oxide (Group III) } \\
\hline Time & Mean & S.D. & $\mathrm{dt} 1 \mathrm{dt} 2$ & Mean & S.D. & $\mathrm{dt} 1 \mathrm{dt} 2$ & Mean & S.D. & $\mathrm{dt} 1 \mathrm{dt} 2$ \\
\hline loading $-12 \mathrm{mon}$ & 0.584 & 0.021 & A a & 0.564 & 0.005 & A a & 0.481 & 0.002 & A a \\
\hline $12-24$ mon & 0.093 & 0.012 & & 0.084 & 0.024 & B & 0.089 & 0.026 & B \\
\hline loading-24mon & 0.677 & 0.015 & A a & 0.648 & 0.017 & A a & 0.57 & 0.013 & A $a b$ \\
\hline
\end{tabular}

S.D.= Standard deviation., Dt1 =Within group Dt $2=$ between groups

Means with the same letter within each row are not significantly different at $(P \leq 0.05)$. 


\section{DISCUSSION}

Although numerous studies have shown that the palate less four-implant retained maxillary overdenture is a simple and effective solution and leads to significant improvement of patient-based outcomes. ${ }^{(4-7)}$ The increased load concentration over the implants may cause loosening of the attachments mucosal ulceration and implant overload ${ }^{(10-12)}$.

The clinical and radiographic findings of this study show that, metallic (cobalt chromium), glass fiber and nano zirconia oxide acrylic resin denture base reinforcement in palateless locator retained maxillary overdenture improve osseointegration .Clinically successful osseointegration was assessed throughout the study period by observing signs of inflammation or infection. Mobility was recorded clinically using the handles of two dental mirrors and no degree of implant mobility was detected. Radiographs are used to evaluate implant success or failure by detecting the peri-implant crestal bone level changes. Successful osseo-integration was indicated by the presence of relatively distinct bone margins with a constant height relative to the implant and direct implant to bone contact.

The mean marginal bone loss between implant loading and the 2-year evaluation was limited in the three studied groups and is comparable with the results reported by other authors. Most radiographic studies suggest that the rate of marginal bone loss after successful implantation is approximately 1.2 $\mathrm{mm}$ in the first year, subsequently tapering off to about $0.1 \mathrm{~mm}$ in succeeding years. ${ }^{(28,29)}$

At the end of 12 months follow-up period, a statistically significant decrease in peri-implant bone height for the posterior implants in the three studied groups was detected. A mean change of $0.64 \mathrm{~mm}$, 0.565 and $0.513 \mathrm{~mm}$ was detected for Group I, II and III respectively. This amount of bone loss was within the permissible range previously reported to occur within the first year of implant placement.
The mean marginal bone loss between the first year and the 2-year evaluation was limited in the three studied groups and is comparable with the results reported by other authors. Most radiographic studies suggest that the rate of marginal bone loss after successful implantation is approximately $1.2 \mathrm{~mm}$ in the first year, subsequently tapering off to about $0.1 \mathrm{~mm}$ in succeeding years A total change of $0.724 \mathrm{~mm}, 0.6855$ and $0.6433 \mathrm{~mm}$ was detected for Group I, II and III respectively at the end of the study.

Many factors play important roles in obtaining successful osseointegration in this study. These include systemic health problems, oral hygiene, quantity and density of bone at the implant recipient site, forces exerted onto the implant and surrounding tissues, type of implant selected, number and distribution of the implant and type of attachment. Careful patient selection and excluding those with medical conditions that may potentially compromise treatment results appears to be important for success. $(30,31)$ The number and position of the implants and are factors which influence the results of this study. The limited vertical height, self-alignment and ability to compensate for divergent implants have been reported as advantage of locator attachment. ${ }^{(27,32)}$

Despite the use of cobalt-chromium alloy frameworks to reinforce the overdentures, the use of metal frameworks has been held in suspicion, given that this increases loading on implants(33) This may account for the significant increase in the amount peri-implant crestal bone level changes for group I (metallic cobalt chromium reinforcement) compared to group II (glass fiber) and group III (nano zirconia oxide) reinforced acrylic resin denture base during the follow up period around posterior implants.

Silanized glass fiber was found to be biocompatible when added to heat-cured resins. Glass fiber reinforcement of acrylic resin denture base material, improved the mechanical properties compared 
to unreinforced acrylic resin denture base material such as; elasticity and hardness, impact strength, rigidity, fatigue resistance and flexural strength and modulus. ${ }^{(14-17)}$ Obvious enhancement in the properties of denture base resin material properties was found with the addition of nano zirconia oxide to polymethylmethacrylate PMMA .Increased its impact strength, flexural strength, ${ }^{(34,35)}$ compressive strength, fatigue strength, as well as its fracture toughness and hardness has been reported.

Since occlusal loading is implicated in crestal bone loss around the implant, the evident changes in measured bone loss between the posterior and anterior implants in the three studied groups may be attributed to the high bite force in the posterior region and the established occlusal scheme Functionally, there was no anterior contact in centric, with light contact during excursive mandibular movement and could account for this finding.

In the present study, all of the patients were more satisfied after wearing palate-less implant retained maxillary overdenture than before treatment, and all of them reported that their functional, phonetic, and chewing abilities improved. In all groups, a number of patients had their opposing prostheses relined during the 2-year period. No biologic complications whether peri-implant mucositis and hyperplasia were observed in the three groups, this could be accounted to the efficient post-insertion care and follow-up performed by both the investigator and the patient.

\section{REFERENCE}

1. Benzing UR, Gall H, and Weber H. (1995) :Biomechanical aspects of two different implant-prosthetic concepts for edentulous maxillae. Int $\mathrm{J}$ Oral Maxillofac Implants. 10(2): 188-198.

2. Adell R, Eriksson B, Lekholm U, Branemark PI, and Jemt T. (1990): Long-term follow-up study of osseointegrated implants in the treatment of totally edentulous jaws. Int $\mathbf{J}$ Oral Maxillofac Implants . 5(4): . 347-359.
3. Kuoppala R and Raustia M (2015): A. Preliminary Observations Regarding Treatment Outcomes in Patients Treated with Maxillary Implant Overdentures in a University Clinic. Int J Prosthodont. 28(6):637-640.

4. El Mekawy N, khalifa AK and Abdualgabbar E ( 2016): The influence of palatal coverage on the retention force and fatigue resistance of mini dental implant maxillary overdenture. J oral Hyg health 10 : 2332-2339.

5. Kumamoto Y, Imamura S and Minakuchi S (2010): Influence of palatal coverage on oral function - oral steregnostic ability and masticatory efficiency. J Prosth Res. 54:92-96.

6. Cavallaro JS and Tarnow DP. (2007): Unsplinted implants retaining maxillary overdentures with partial palatal coverage: report of 5 consecutive cases. Int J Oral Maxillofac Implants. 22(5): 808-814.

7. José Balaguer 1, Berta García 1, Maria Peñarrocha 1, Miguel Peñarrocha (2011) :Satisfaction of patients fitted with implant-retained overdentures. Med Oral Patol Oral Cir Bucal.. 1;16 204-209.

8. Sadowsky SJ (2007): Treatment considerations for maxillary implant overdentures : A systemic review. J Prosthet Dent. 97:340-348.

9. Damghani, S., Masri, R., Driscoll, C.F., and Romberg, E.(2012) : The effect of number and distribution of unsplinted maxillary implants on the load transfer in implantretained maxillary overdentures: an in vitro study. J Prosthet Dent, . 107(6):358-365.

10. Takahashi T, Gonda T and Maeda Y (2016) : Effect of reinforcement on denture stains in maxillary overdenture: An invitro study under various implant configurations. MaxilloFac Implants, 31 (6) :162- 167.

11. Takahashi T, Gonda T and Maeda Y (2017) : Can reinforcement of maxillary implant overdenture decrease stress on underlying implants ?. Int J Oral Maxillofac Implants. 32:63-69.

12. Gibreel MF, Kahalifa AK, Said MM, Mahann F, El-Amir N, Nahri TO, et al (2019) : Biomechanical aspect of reinforced implant overdenture : A systematic review, J Mech Behav Biomed mate.91 : 202-211.

13. Jagger DC, Harrison A. and Jandt KD (1999): The reinforcement of dentures (review). J Oral Rehabil. 26:185-194.

14. Gad MM, Fouda1SM, Al-Harbi1FA, Näpänkangas R and Raustia A (2017) : PMMA denture base material enhancement: a review of fiber, filler, and nanofiller addition. Int J Nanomedicine.:12 3801-3812. 
15. Alla R, Sajjan S, Alluri V, Ginjupalli K and Padhya NU (2013). Influence of fiber reinforcement on the properties of denture base resins. J Biomat Nano-Biotechnol.4:91-97.

16. Tacir IH, Kama JD, Zortuk M, and Eskimez S (2006). Flexural properties of glass fiber reinforced acrylic resin polymers. Aust Dent J.51:52-56.

17. Moreno MV, Acosta-Torres LS, Barcel O-Santana FH, Vanegas-Lanc RD, Plata-Rodríguez ME and Casta VM (2012). Fiber-reinforced nano-pigmented poly (methyl methacrylate) as improved denture base. J Appl Polym Sci. 126:289-296.

18. Hamouda IM and Beyari MM (2014). Addition of glass fibers and titanium dioxide nanoparticles to the acrylic resin denture base material: comparative study with the conventional and high impact types. Oral Health Dent Manag. 13:107-112.

19. Singh K, Sharma SK, Negi P, Kumar M, Rajpurohit D and Khobre P (2016). Comparative evaluation of flexural strength of heat polymerized denture base resins after reinforcement with glass fibers and nylon fibers: An in vitro Study. Adv Hum Biol.;6:91-94.

20. Denry I. and Kelly J(2008).: State of the art zirconia for dental applications. Dent. Mat. 4:299-307.

21. Neveen M. Ayad, Manal F. Badawi and Abdou A. Fatah(2008).: Effect of Reinforcement of high impact acrylic resin with Zirconia on some physical and mechanical properties. Rev. Clin. Pesq. Odontol. 4: 145-51.

22. Rita D., Holger Z., Michelle O., Christian N., Hans-Peter W. and Hans-Christoph L ( 2008):: Osseointegration of zirconia implants compared with titanium: an in vivo study. Head \& Face Med. 4:30-36.

23. Ihab NS. and MoudhaffarM (2011).: Evaluation the effect of modified nano-fillers addition on some properties of heat cured acrylic denture base material. J Bagh College Dentistry. 23(3):23-9.

24. Scarfe, W.C., Farman, A.G., and Sukovic, P (2006).: Clinical applications of cone-beam computed tomography in dental practice. J Can Dent Assoc, 72(1): 75-80.

25. Yoshida K. AND Greener EH (1994).: Effects of coupling agents on mechanical properties of metal oxide polymethacrylate composites. J Dent.;22(1):57-62.
26. Frederiksen NL (1995). Diagnostic imaging in dental implantology. Oral Surg Oral Med Oral Pathol Oral Radiol Endod. 80: 540-554.

27. Wang F, Monje A, Huang W, Zhang Z and Wang G (2015): Maxillary four implant- retained overdenture via locator attachment : intermediate -term results from a retrospective study . Clinical Implant Dentistry and Related Research. 18: 747-767.

28. Benson B.W.and Shetty V. Dental Implants, In: Oral Radiology Principles and Interpretation, S.C. White \& M. J. Pharoah, , St. Louis, Missouri, Mosby, Elsevier, 2009.

29. Eerdekens, L., Schols, M., Coelst, L., Quirynen,M. and Naert, I. (2015) A 5-year prospective study on cone-anchored implants in the edentulous maxilla. Clinical Implant Dentistry and Related Research. 17 (2) : 621-632.

30. Pjetursson, B.E., Tan, K., Lang, N.P., Bragger, U., Egger, M., and Zwahlen, M (2004).: A systematic review of the survival and complication rates of fixed partial dentures (FPDs) after an observation period of at least 5 years. Clin Oral Implants Res, 15(6): 625-42.

31. Sadowsky SJ and zitzmann NU (2016) : Protocols for maxillary implant overdentures : A systemic review. Int J Oral Maxillofac Implants. 31:182-191.

32. Rabbani S, juszcyk AS, Clark RK, and Radford DR, (2015): Investigation of retentive force reduction and wear of the locator attachment system with different implant angulation . Int J Oral Maxillofac Implant.30 93): 31-35.

33. Davis DM, Packer ME. Mandibular overdentures stabilized by Astra Tech implants with either ball attachments or magnets: 5-year results. Int J Prosthodont 1999;12: 222-229.

34. Safi IN ,and Moudhaffar M (2011). Evaluation the effect of modified nano fillers addition on some properties of heat cured acrylic denture base material. J Bagh Coll Dent. 23:23-29.

35. Zhang XJ, Zhang XY, Zhu BS, and Qian C (201). Effect of nano $\mathrm{ZrO}_{2}$ on flexural strength and surface hardness of polymethylmethacrylate. Shanghai Kou Qiang Yi Xue. 2011;20:358-363. 